\title{
Efficient Three-Fold Symmetrical Nanographene Synthesis
}

\section{Key words}

nanographenes

Friedel-Crafts

reaction

Scholl reaction<smiles>BrCc1cc(CBr)cc(CBr)c1</smiles>

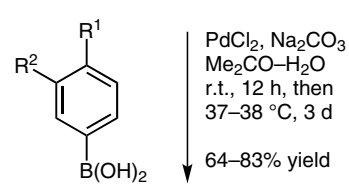<smiles>[R7]c1cccc(Cc2cc(Cc3ccc([R7])c([R7])c3)cc(Cc3ccc([R7])c([R7])c3)c2)c1</smiles>

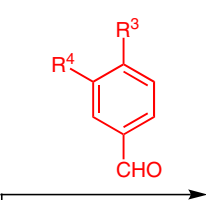

$10 \mathrm{~mol}_{2} \mathrm{FeCl}_{3}, \mathrm{Ac}_{2} \mathrm{O}$

$\mathrm{CH}_{2} \mathrm{Cl}_{2}, \mathrm{MeNO}_{2}$, argon

r.t.; then excess $\mathrm{FeCl}_{3}$

24 examples

$39-97 \%$ yield

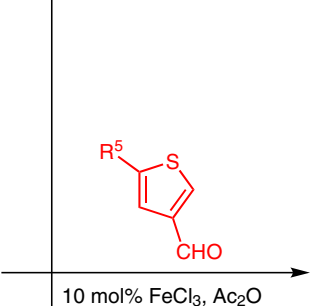

$10 \mathrm{~mol}_{2} \mathrm{FeCl}_{3}, \mathrm{Ac}_{2} \mathrm{O}$
$\mathrm{CH}_{2} \mathrm{Cl}_{2}, \mathrm{MeNO}_{2}$, argon



3 examples

$32-47 \%$ yield

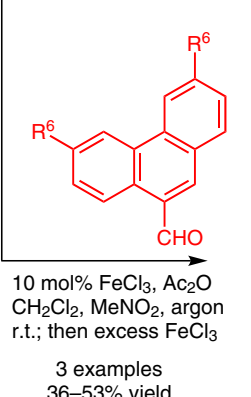

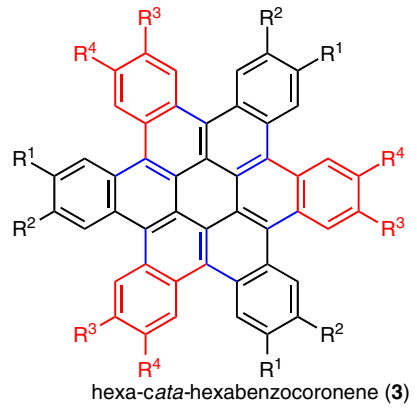

SYNFACThen
Significance: An efficient synthesis of nanographenes is reported. The key is recognizing that hexa-cata-hexabenzocoronene (c-HBC) possesses three-fold symmetry and that only seven of the 13 benzene rings are enough to build up c-HBC. 2 reacts with three equivalents of an aromatic aldehyde via Friedel-Crafts and Scholl reaction.
Comment: Alkoxy groups for $\mathrm{R}^{1}$ and $\mathrm{R}^{2}$ were employed to generate electron-rich compound $\mathbf{2}$ which is more reactive towards Friedel-Crafts and Scholl reaction. Bromo-substituted $\left(\mathrm{R}^{3}\right) \mathrm{c}-\mathrm{HBC}$ can be potentially utilized to prepare more functionalized nanographenes. 